\title{
Size effect in the fracture properties of sandwich panels of plasterboard and core of rock wool
}

\author{
J. A. Alonso ${ }^{\mathrm{a}}$, E. Reyes ${ }^{\mathrm{b}}$, J.C. Gálvez ${ }^{\mathrm{b}} \bowtie$ \\ a. Departamento de Tecnología de la Edificación, E.T.S. Edificación. Universidad Politécnica de Madrid. (Madrid, Spain) \\ b. Departamento de Ingeniería Civil: Construcción, E.T.S Ingenieros de Caminos, Canales y Puertos. \\ Universidad Politécnica de Madrid. (Madrid, Spain) \\ $\triangle$ jaime.galvez@upm.es
}

\author{
Received 16 October 2017 \\ Accepted 2 August 2018 \\ Available on line 13 February 2019
}

\begin{abstract}
This paper extends the previous work of the authors and deals with the study of fracture of sandwich panels of plasterboard and rock wool under in-plane bending and tensile loading. It presents the results of the experimental campaign focused on the size effect of the tested specimens. To this end, mixed-mode (I and II) fracture tests have been carried out with specimens of three different sizes. The experimental results are compared with the values obtained from the numerical simulation of the test by using a model based on the embedded cohesive crack developed by the authors in previous published works. Comparison of the results shows how the model is able to reproduce the size effect of the specimens in this material from the parameters that characterize fracture behaviour. The aim is to use the cohesive model proposed by the authors to move from laboratory tests to a built panel.
\end{abstract}

KEYWORDS: Gypsum; Method of finite elements; Flexural strength; Mechanical properties; Modelization.

Citation/Citar como: Alonso, J.A.; Reyes, E.; Gálvez, J.C. (2019) Size effect in the fracture properties of sandwich panels of plasterboard and core of rock wool. Mater. Construcc. 69 [333], e181 https://doi.org/10.3989/mc.2019.10617

RESUMEN: Efecto tamaño en las propiedades de fractura de paneles sándwich de yeso laminado y alma de lana de roca. Este artículo extiende el trabajo de los autores y aborda el estudio de la fractura en flexión en su plano de paneles de sándwich de yeso laminado y lana de roca. Se presentan los resultados experimentales del estudio del efecto tamaño de fractura en modo mixto (modos I y II) de probetas de tres tamaños. Los resultados experimentales se comparan con los obtenidos de la simulación numérica empleando un modelo de fisura cohesiva embebida presentado por los autores en trabajos previos. El resultado muestra que el modelo reproduce adecuadamente el efecto de tamaño en fractura de los paneles ensayados a partir de los parámetros de caracterización del material. El modelo usado facilita el paso de los resultados de laboratorio al panel construido.

PALABRAS CLAVE: Yeso; Análisis de elementos finitos; Resistencia a la flexión; Propiedades mecánicas; Modelización.

ORCID ID: J.A. Alonso (http://orcid.org/0000-0002-0391-994X); E. Reyes (http://orcid.org/0000-0002-1284-7335); J.C. Gálvez (http://orcid.org/0000-0001-9106-2917)

Copyright: (C) 2019 CSIC. This is an open-access article distributed under the terms of the Creative Commons Attribution 4.0 International (CC BY 4.0) License. 


\section{INTRODUCTION}

The use of sandwich panels is a solution increasingly used in the construction industry to the detriment of the traditional brick masonry for interior vertical partition of a self-supporting frame. One of the main reasons for this expansion is significant advantage associated with velocity of execution when compared with other solutions and those related to the processes of dry construction.

Sandwich panels made from laminated plasterboard and rock wool provide some characteristics of strength and acoustic insulation that are superior to other materials used in self-supporting frames. For adapting to the Spanish Technical Code for Building, and more specifically the DB-HR: "Protection against noise" (1), minimum requirements for airborne noise insulation for interior partitions should be met. Traditional brickwork masonry provides a general index of acoustic absorption (RA) of $33 \mathrm{dBA}$, and self-supporting frame elements $43 \mathrm{dBA}$. In addition, the Spanish Catalogue of Building Elements (CTE) (2) shows that traditional partition of masonry with hollow brick of $70 \mathrm{~mm}$, and finished with $15 \mathrm{~mm}$ plasterwork and roughcast of plaster at both sides, provides a RA of $36 \mathrm{dBA}$. Likewise, this paper shows how partitions of self-supporting frame with 48 $\mathrm{mm}$ of rock wool and laminated plasterboard of $15 \mathrm{~mm}$ at both sides provide a RA of $43 \mathrm{dBA}$. This saving in partition thickness, together with a higher RA, justifies the expansion of use of this type of partition in new buildings.

Requirements associated with quality control, both in rehabilitation and in new building works, require that partitions and vertical construction elements be prevented from cracking. One of the most frequent cracking pathologies is caused by excessive deformation of the slabs where the vertical partitions are supported. In such a type of failure, one or a number of cracks of a considerable size appear, which is a typical problem in the case of cracking by tensile and shear stress (3-5).

In a previous published work, the authors obtained the experimental parameters to evaluate fracture behaviour of sandwich panels made from laminated plasterboard and rock wool (6). These experimental results were used to simulate fracture with a numerical model with an embedded crack that has been used by the authors in the numerical simulation of the fracture of several quasi-brittle materials (3-5). The numerical simulations provide a significant degree of accuracy when applied to the results obtained from the experiments. The numerical modelling reproduces the formation and propagation of the cracks under mixed-mode load (mode I and II of fracture).
The size effect of an element is a significant property of the fracture behaviour of the material. It could be defined as the strength variation of a structural element as its size increases. Such an effect is caused, among other factors, by an increase of the stored energy under deformation as the element size increases (when it is released at the crack tip, the cracking propagation is accelerated). Cohesive fracture models lead to an asymptotic law similar to the size effect approach provided by Bažant $(7,8)$.

In order to study the influence of the size of the sandwich panels made from laminated plasterboard and rock wool, in the present work a series of mixedmode fracture tests on three sizes of specimens was first carried out. Then a cohesive crack model, implemented into a finite element with an embedded crack, was used to simulate the tests, using as an input the parameters obtained from the experiments performed in a previous work (6) and obtaining a good approximation of the experimental results. This paper also includes the study of crack growing under mixed-mode loading (type modes I and II).

\section{EXPERIMENTAL CAMPAIGN}

As mentioned above, the excessive deflection of the slabs causes cracking of the vertical elements. Typically, in this type of failure, one or a discrete number of cracks of a considerable size appear. This is a characteristic problem of cracking by tensile and shear stresses. In this work, a series of mixedmode tests with an asymmetric notch on specimens of three different sizes was carried out with the aim of studying the size effect.

\subsection{Materials}

The sandwich panels were formed by two sides of laminated plasterboard and fixed by using cold polyurethane glues applied to a core of $170 \mathrm{~kg} / \mathrm{m}^{3}$ density rock wool.

The specimens needed for performing the tests were obtained from supplied commercial sandwich panels. The laminated plasterboard and the rock wool complied with the standards UNE EN 520 (9) and UNE EN 13.162 (10), respectively.

\subsection{Specimens}

The specimens needed for performing the tests were obtained from received commercial sandwich panels. The panels used were formed by two sides of laminated plasterboard with a $12 \mathrm{~mm}$ thickness and a insulating core of $50 \mathrm{~mm}$ thickness, following the recommendation RILEM TC 89-FMT (1990) (11) to study the size effect, with a ratio of height of two. The length of the specimens varied, being always 4.25 times the height. The notch length measured 


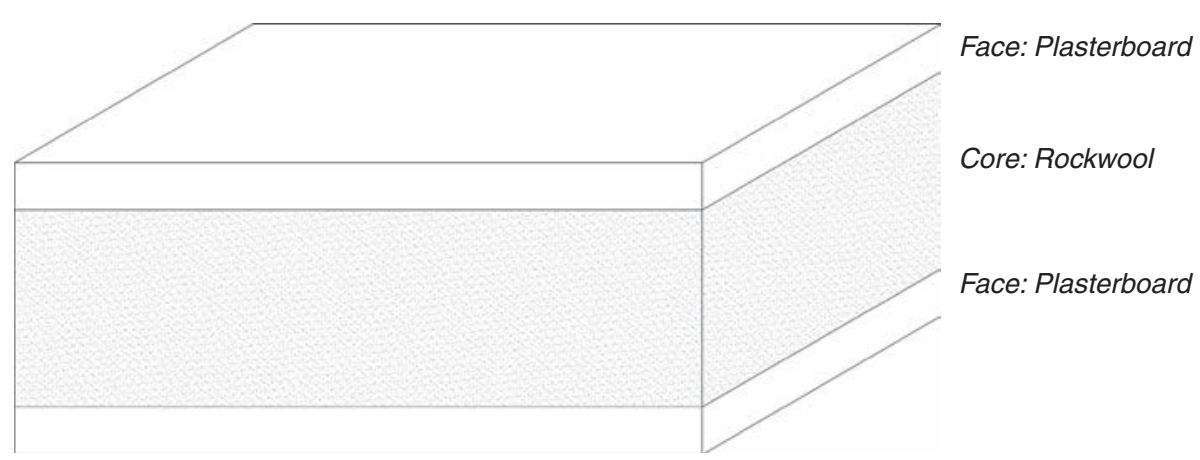

FIGURE 1. Sketch of the sandwich panel with plasterboard surfaces and rock wool core.

TABLE 1. Dimensions of the specimens for size effect testing.

\begin{tabular}{lcccc}
\hline & \multicolumn{4}{c}{ Size $(\mathrm{mm})$} \\
\cline { 2 - 5 } $\begin{array}{l}\text { Sandwich Panel } \\
e-E L R-e\end{array}$ & $\begin{array}{c}\text { Length } \\
(L)\end{array}$ & $\begin{array}{c}\text { Thickness } \\
(B)\end{array}$ & $\begin{array}{c}\text { Depth } \\
(D)\end{array}$ & $\begin{array}{c}\text { Notch depth } \\
(h)\end{array}$ \\
\hline $12-50-12$ & 314.5 & 74 & 74 & 37 \\
& 637.5 & 74 & 150 & 75 \\
& $1,232.5$ & 74 & 290 & 145 \\
\hline
\end{tabular}

$e=$ thickness of plasterboard surface $(\mathrm{mm})$.

$E L R=$ thickness of the rock wool core (mm)

half the height of the specimen. Table 1 shows the dimension specimens used in the tests.

\subsection{Test method}

In order to perform the bending test with an asymmetric notch, the geometry used was a slightly modified version of that proposed by Reyes (12) to study the asymmetric bending of brick work masonry. This variation was due to the first experimental results of the tests carried out on the specimens with a height greater than $74 \mathrm{~mm}$. In this case the failure was caused by the crushing of the laminated plasterboard of the sandwich panel. Therefore, the asymmetry of the notch in relation with the supports and the load was amended with the aim of correcting the problem.

Figure 2 shows the asymmetric three-point bending test arrangement, with the dimensions of the specimen parameterised according to the height D.

The load was applied with the actuator through a steel roller with a diameter of $10 \mathrm{~mm}$. The specimen was supported on two steel rollers with the same dimensions. In order to avoid local crushing of the specimen in the support zone, two aluminium plates of $70 \times 20 \times 4 \mathrm{~mm}$ were glued at two such zones. The rollers of the supports were supported at the same time on an anti-torsion hinge. Lastly, the entire set rested on a linear guide of rollers that enabled sliding on the supporting plane, with a friction value of virtually nil. In such a way, the supports were hinges that allowed turning in all directions and horizontal sliding. The supporting plane was materialised by a highly rigid metallic beam, bolted to the bottom of the testing machine frame. With the aim of performing the bending tests in the specimens of $290 \mathrm{~mm}$ height, it was necessary to use an additional device, as the span between the support (see Figure 2) obliged one of them to lie outside the testing machine.

During the test, the vertical displacement of the load application point, the crack mouth opening displacement and the applied load were recorded. The test was controlled by the load application point displacement with a steady speed of $0.04 \mathrm{~mm} / \mathrm{min}$. Once the test finished, the crack trajectory was obtained.

\subsection{Equipment and instrumentation}

All the tests were performed with a universal electro-mechanical testing machine SERVOSIS ME $405 / 1$, with a load capacity of $10 \mathrm{kN}$. Depending on the size, the tooling and instrumentation were adjusted for each test. The testing machine can receive the analogue signal of four independent transducers. Two of them belong to the basic machine configuration to measure the applied load and the displacement of the actuator. It also included two resistive extensometers HBM DA1 of $\pm 2,5 \mathrm{~mm}$ of range, in order to measure the load application point displacement and the crack mouth opening displacement (CMOD).

\section{EXPERIMENTAL RESULTS}

Figure 3 shows the experimental load versus the load application point displacement for the asymmetric bending tests of the sandwich panels 12-50-12.

The experimental crack trajectory obtained progressed from the tip of the notch to the load application point, as expected. Figure 4 shows an example.

Figure 5 shows the experimental crack trajectories obtained in all the tests. 


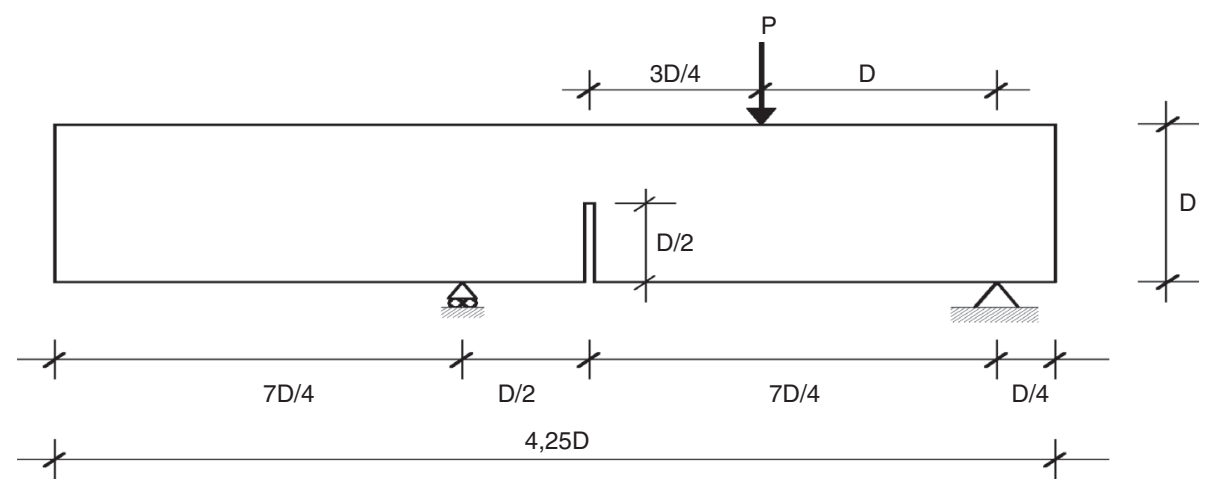

FIGURE 2. Testing arrangement, geometry and dimensions of the fracture specimens under non-symmetric bending test.
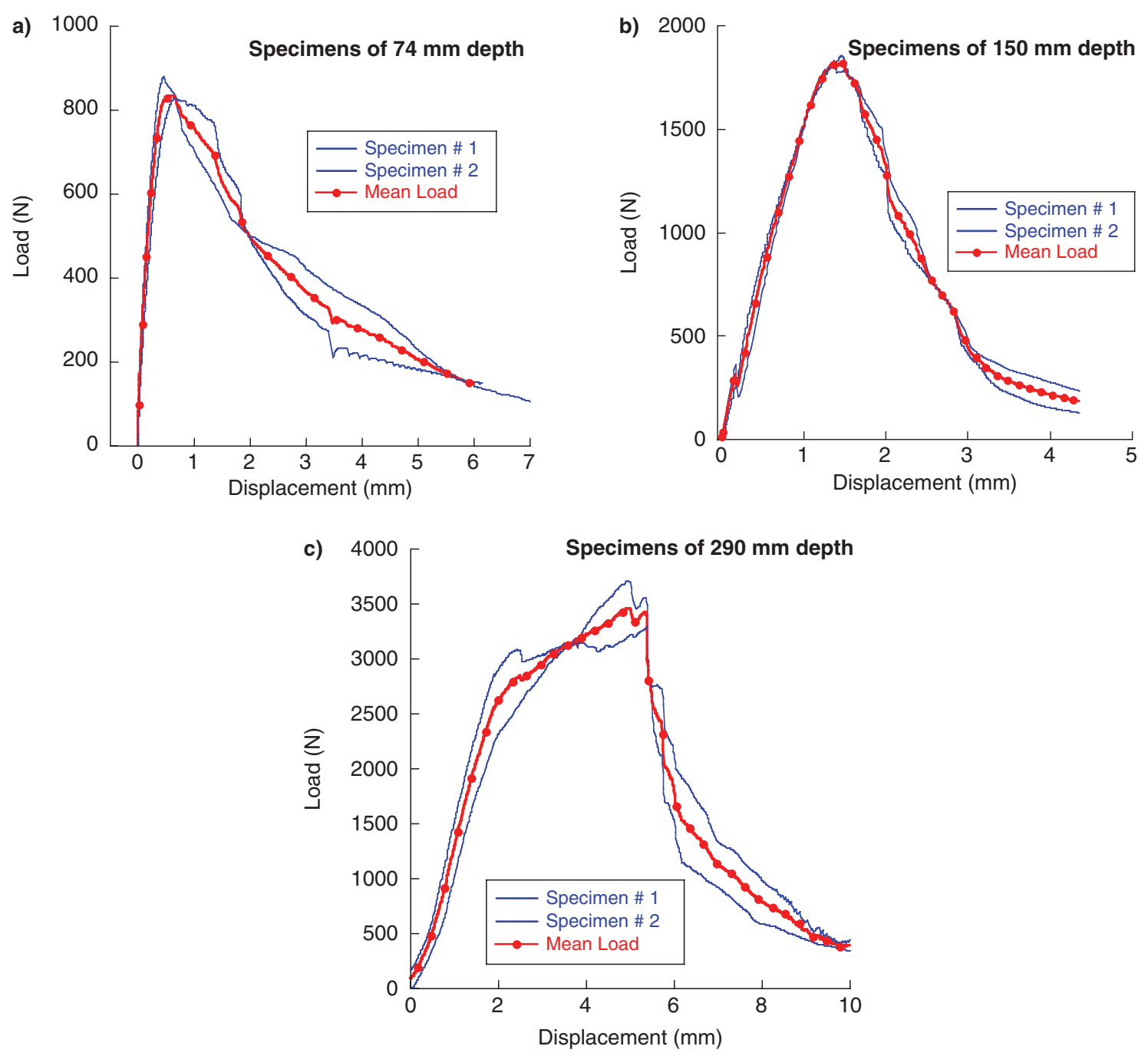

FIGURE 3. Fracture experimental results of the mixed-mode fracture tests for different size specimens of 12-50-12 panel sandwich: a) $74 \mathrm{~mm}$ depth, b) $150 \mathrm{~mm}$ depth, c) $290 \mathrm{~mm}$ depth.

Figure 6 shows the size effect with the error bars (standard deviation) for the values obtained for all the specimens of 74, 150 and $290 \mathrm{~mm}$ height.

In the graphic the nominal stress values have been parameterised by dividing them by the ultimate stress.
Similarly, the height has been parameterised by using the characteristic length as defined by Bažant, Z.P and Planas, J. (13) with the expresssion [1]:

$$
l_{c h}=\frac{E \cdot G_{F}}{f_{t}^{2}}
$$

Materiales de Construcción 69 (333), January-March 2019, e181. ISSN-L: 0465-2746. https://doi.org/10.3989/mc.2019.10617 


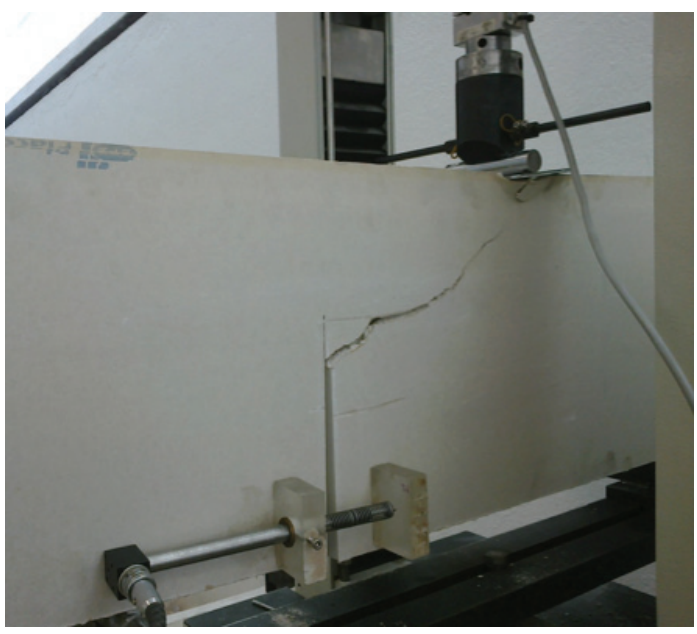

Figure 4. Specimen of sandwich panel of $150 \mathrm{~mm}$ depth under non-symmetric bending test.
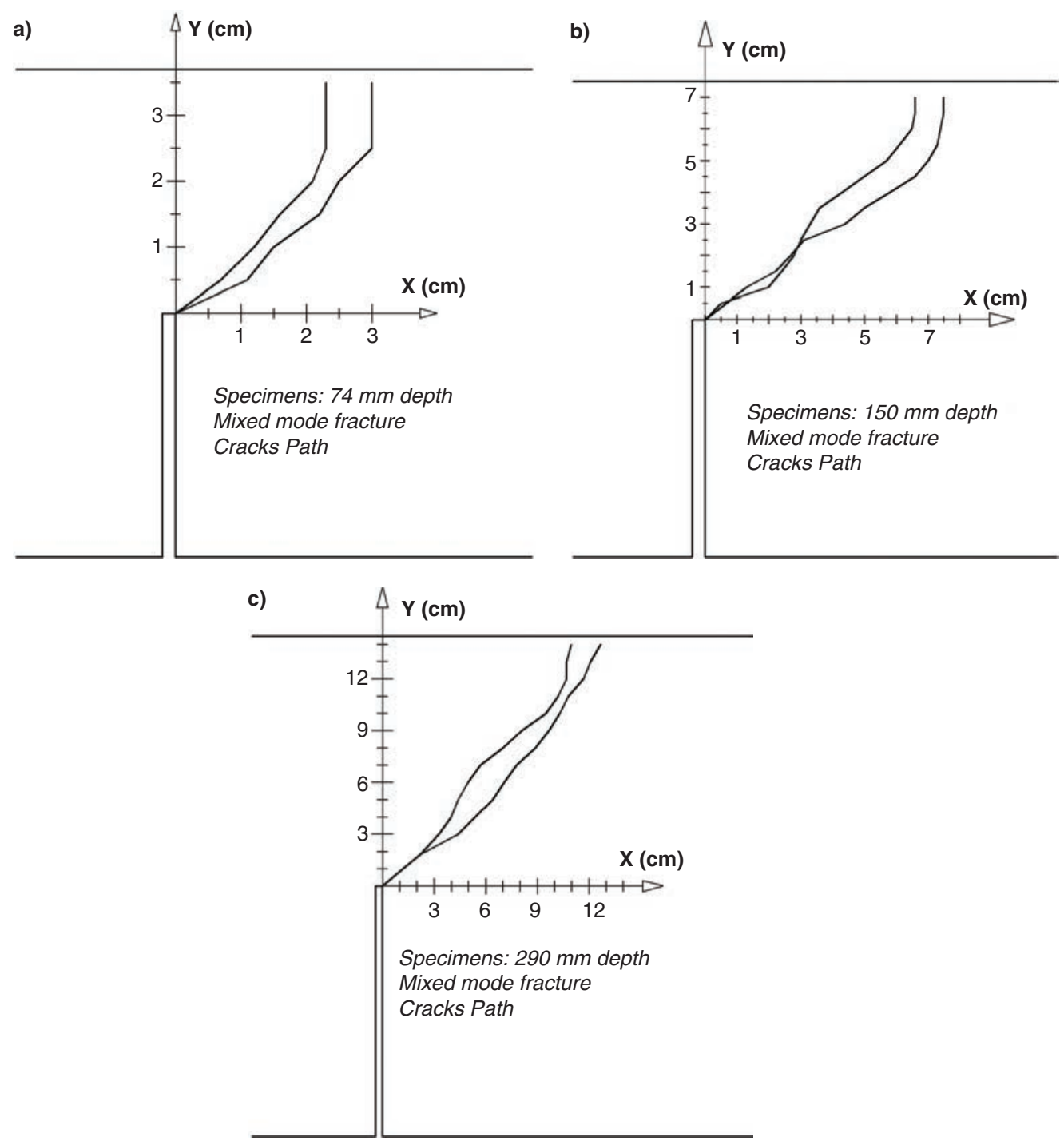

FIGURE 5. Experimental records of the mixed-mode crack paths, for specimens tested of 12-50-12 panel sandwich: a) $74 \mathrm{~mm}$ depth,

b) $150 \mathrm{~mm}$ depth, c) $290 \mathrm{~mm}$ depth.

where $\mathrm{E}$ is the modulus of elasticity, $\mathrm{G}_{\mathrm{F}}$ the specific fracture energy and $f_{t}$ the tensile strength, with each having been obtained in a previous work (6).

As may be noted, the size effect in this material is significant. In this case, the normal size effect of quasi-brittle materials is combined with high fracture energy. As the size of the element increases, the deformation energy stored increases; when this is released at the crack tip, crack propagation is accelerated.

\section{OVERVIEW OF THE COHESIVE NUMERICAL MODEL}

This subsection summarises the numerical model adopted for the simulation of the fracture tests. The model is based on the cohesive approach, offered by Bareblatt (14) and Dugdale (15) and applied to 


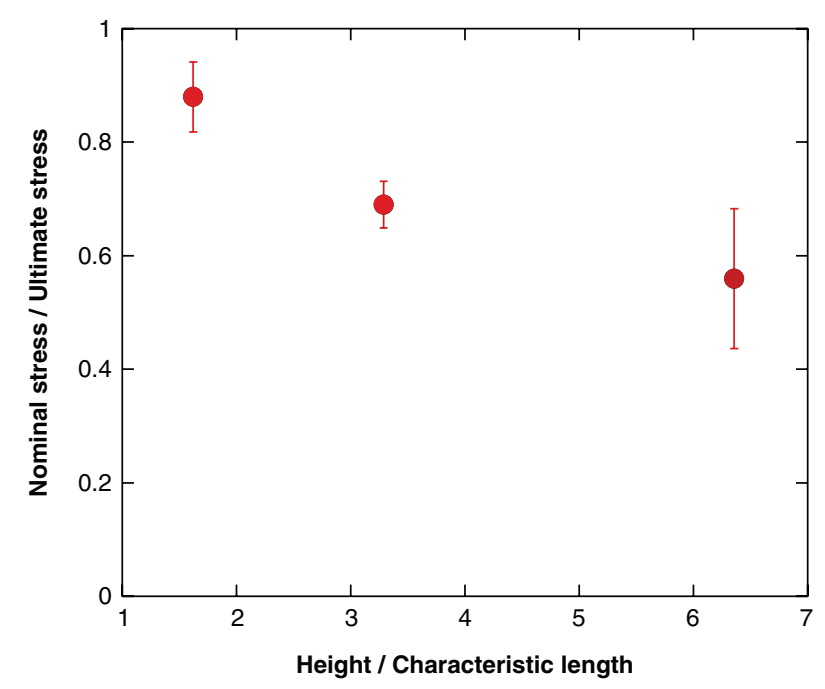

FiguRE 6. Experimental records. Graphic of size effect for specimens of 74, 150 and $290 \mathrm{~mm}$ depth, of 12-50-12 panel sandwich.

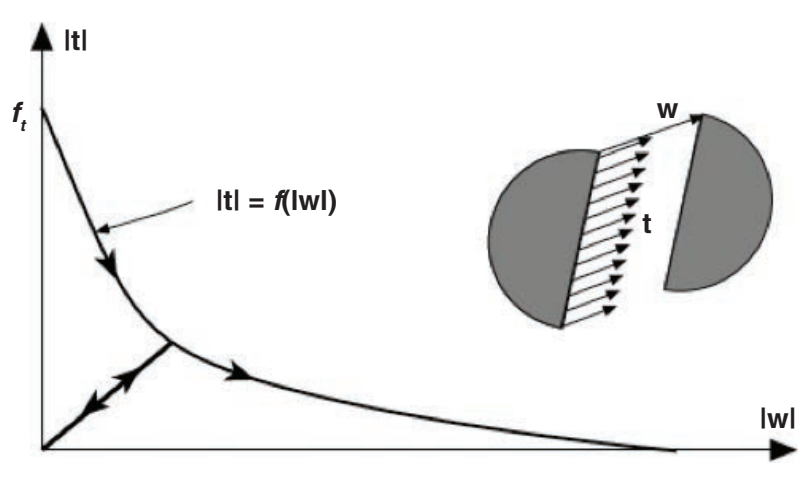

FIGURE 7. Sketch of the softening curve, with unloading branch, and central force model for the cohesive crack model. concrete by Hillerborg et al. (16). It has since been applied to the study of fracture of quasi-brittle materials.

Previous works showed that for most of the experiments described in the literature, cohesive crack growth takes place under predominantly local mode I, which implies that the overall behaviour is dominated by mode I parameters (17-20). Therefore, in this work, a simple generalisation of the cohesive crack to mixed mode is used which assumes that the traction vector $\mathbf{t}$ transmitted across the crack faces is parallel to the crack displacement vector $\mathbf{w}$ (the central forces model). For monotonic loading in which the magnitude of the crack opening vector $|\mathbf{w}|$ is never decreasing, the relationship reads as follows [2]:

$$
\mathbf{t}=f(|\mathbf{w}|) \frac{\mathbf{w}}{|\mathbf{w}|}
$$

where $f(|\mathbf{w}|)$ is the classical softening function for pure opening mode (Figure 7). In order to address the possibility of unloading, it is further assumed that the cohesive crack unloads at the origin (Figure 7), Equation [2] is rewritten as follows [3]:

$$
\mathbf{t}=\frac{f(|\widetilde{w}|}{\widetilde{w}} \mathbf{w} \text { with } \widetilde{w}=\max (|\mathbf{w}|)
$$

where is $\widetilde{w}$ is an equivalent crack opening defined as the historical maximum of the magnitude of the crack displacement vector.

Figure 8a shows an arbitrary classical finite element defined by a node layout. A straight crack is assumed to be embedded in it. As Figure 8b shows, the crack splits the element in the two sub-domains $A^{+}$and $A^{-}$. One of the faces of the crack is taken as the reference, in this case the corresponding with the sub-domain $A^{-}$, with its normal $\mathbf{n}$ pointing towards
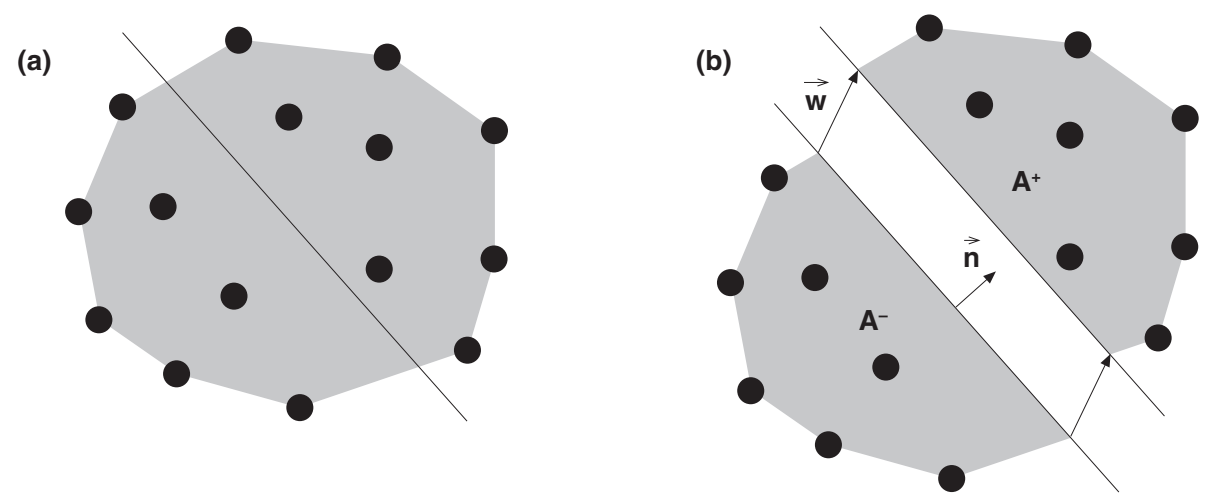

FIGURE 8. Finite element with a crack with uniform opening: a) generic element with nodes and crack line, b) displacement jump across the crack line 
the other face as the positive normal. Let $\mathbf{w}$ be the displacement jump across the crack of the opposite side of the crack with respect to the reference side (see Figure $8 \mathrm{~b}$ ). Following the strong discontinuity approach (SDA) (21), the approximate displacement field within the element can be written as follows [4]:

$$
\mathbf{u}(\mathbf{x})=\sum_{a \in A} N_{a}(\mathbf{x}) \mathbf{u}_{a}+\left[H(\mathbf{x})-N^{+}(\mathbf{x})\right] \mathbf{w}
$$

where $a$ is the element node index, $N_{a}(\boldsymbol{x})$ the traditional shape function for node $a, \mathbf{u}_{a}$ the corresponding nodal displacement, $H(\boldsymbol{x})$ the Heaviside jump function across the crack plane, which represents a unit step placed along the crack line that also can be defined as the integral of the Dirac's $\delta$ function on the crack line [i.e., $H(\boldsymbol{x})=0$ for $\mathbf{x} \in A^{-}$, $H(\boldsymbol{x})=1$ for $\left.\mathbf{x} \in A^{+}\right]$, and $N^{+}(\mathrm{x})=\sum_{a \in A^{+}} N_{a}(\mathbf{x})$.

The strain tensor is obtained from the displacement field as a continuous part $\varepsilon^{c}$ plus Dirac's $\delta$ function on the crack line. The continuous part, which determines the stress field on the element on both sides of the crack, is given by the following [5]:

$$
\varepsilon^{c}(\mathbf{x})=\varepsilon^{a}(\mathbf{x})-\left[\mathbf{b}^{+}(\mathbf{x}) \otimes \mathbf{w}\right]^{s}
$$

where $\varepsilon^{\mathrm{a}}$ and $\mathbf{b}^{+}$are given by [6] and [7]

$$
\begin{gathered}
\boldsymbol{\varepsilon}^{c}(\mathrm{x})=\sum_{a \in A}\left[\mathbf{b}^{+}(\mathbf{x}) \otimes \mathbf{u}_{a}\right]^{s} \\
\mathbf{b}^{+}(\mathbf{x})=\sum_{a \in A^{+}} \mathbf{b}_{a}(\mathbf{x})
\end{gathered}
$$

with $\mathbf{b}_{\mathbf{a}}(\mathbf{x})=\operatorname{grad} \mathbf{N}_{a}(\mathbf{x})$ and superscript ${ }^{S}$ indicating a symmetric part of a tensor. Obviously, $\varepsilon^{\mathrm{a}}$ is the apparent strain tensor of the element computed from the nodal displacements.

In order to simplify the computations, the bulk behaviour (material outside the crack) is assumed to be linear-elastic and isotropic, although this approximation could be relaxed if necessary (e.g. (4)). The crack displacement vector $\mathbf{w}$ is handled as two internal degrees of freedom which are solved at the level of the crack within the finite element (assumed to be a constant strain triangle).

One of the main tasks of the implementation is to compute the stress tensor in the element, which follows an algorithm similar to plasticity. The stress tensor is given by Equation [5] and the hypothesis of elastic bulk material behaviour is adopted. Then the stress tensor in the element is expressed as follows [8]:

$$
\sigma=\mathbf{E}:\left[\varepsilon^{a}-\left(\mathbf{b}^{+} \otimes \mathbf{w}\right)^{s}\right]
$$

where $\mathbf{E}$ is the tensor of elastic moduli. Before computing the result of the stress, the crack displacement should be solved. Along the cohesive crack line, the jump vector $\mathbf{w}$ and the traction vector $\mathbf{t}$ are to be related by Equation [2]. For the exact solution, the traction vector is computed locally as [9]:

$$
\mathbf{t}=\sigma \cdot \mathbf{n}
$$

For the finite element, however, the approximate tractions and crack jump vectors should be considered. To simplify the reasoning, the traction field along the crack line is approximated by a constant traction $\mathbf{t}$. The corresponding equation is obtained by substituting the foregoing expression by the stress [8] into Equation [9] and the result into the cohesive crack Equation [2]. The resulting condition is as follows [10]:

$$
\frac{f(\widetilde{w})}{\widetilde{w}} \mathbf{w}=\left[\mathbf{E}: \varepsilon^{a}\right] \mathbf{n}-\left[\mathbf{E}:\left(\mathbf{b}^{+} \otimes \mathbf{w}\right)^{s}\right] \mathbf{n}
$$

which can be rewritten as [11]

$$
\frac{f(\widetilde{w})}{\widetilde{w}} \mathbf{w}=\left[\mathbf{E}: \varepsilon^{a}\right] \cdot \mathbf{n}-\left[\mathbf{n} \cdot \mathbf{E} \cdot \mathbf{b}^{+}\right] \mathbf{w}
$$

or [12]

$$
\left[\frac{f(\widetilde{w})}{\widetilde{w}} \mathbf{1}+\mathbf{n} \cdot \mathbf{E} \cdot \mathbf{b}^{+}\right] \cdot \mathbf{w}=\left[\mathbf{E}: \varepsilon^{a}\right] \mathbf{n}
$$

where $\mathbf{1}$ is the second-order unit tensor. This equation is solved for $\mathbf{w}$ by using the NewtonRaphson method given the nodal displacements (and so $\varepsilon^{\mathrm{a}}$ ) once the crack is formed with $\mathbf{n}$ and $\mathbf{b}^{+}$ thus also being obtained.

One of the key points in the proposed method entails how the crack is introduced in the element (that is to say, how $\mathbf{n}$ and $\mathbf{b}^{+}$are determined).

Initially, $\mathbf{w}=0$ in the element and $\mathbf{n}$ and $\mathbf{b}^{+}$are undefined. Thus, the element loads elastically and $\sigma=\mathbf{E}: \varepsilon^{a}$ until the tensile stress reaches tensile strength in a particular direction. Then a crack is introduced perpendicularly to the direction of the tensile stress that reached the tensile strength, with $\mathbf{n}$ being computed as a unit eigenvector of $\sigma$. In the case of a constant strain triangle finite element, a triangle with three nodes, the crack always divides the element with a unique node on one side of the line, called the solitary node, and two nodes on the other side.

Next, the solitary node and the vector $\mathbf{b}^{+}$are determined by requiring the angle between $\mathbf{n}$ and $\mathbf{b}^{+}$to be the smallest possible (see Figure 9). Given that this is based on the tensor $\mathbf{n} \cdot \mathbf{E} \cdot \mathbf{b}^{+}$, the tangent stiffness matrix is well conditioned when $\mathbf{n}$ and $\mathbf{b}^{+}$tend to be parallel. In such a way, the pathological situations with $\mathbf{n} \cdot \mathbf{E} \cdot \mathbf{b}^{+}$almost orthogonal are avoided. For a constant strain triangle finite 
(a)

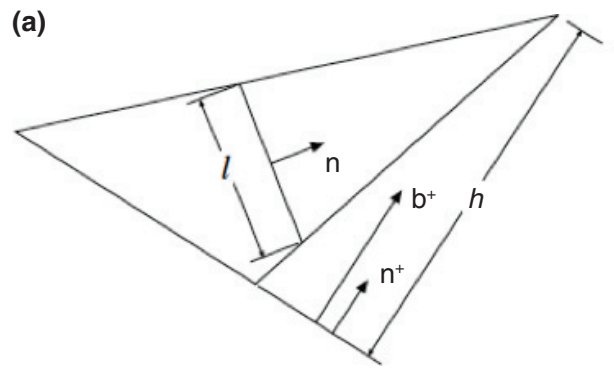

(b)

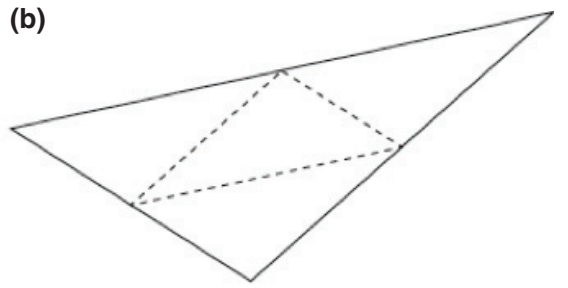

FIgURE 9. Constant stress triangle: a) geometrical definitions, b) potential crack paths satisfying both global and local equilibrium (dashed lines).

element, and given the direction of cracking, there are only three modes of separating the nodes in two subelements. This is algorithmically achieved by looping over the three possible vectors $\mathbf{b}^{+}$and looking for the one that satisfies [13]:

$$
\frac{\left|\mathbf{b}^{+} \cdot \mathbf{n}\right|}{\left|\mathbf{b}^{+}\right|}=\max
$$

Additional details of the model may be found in $\operatorname{ref}(3,4)$.

\section{NUMERICAL ANALYSIS OF THE FRACTURE TESTS}

The described model has been included in the commercial finite element code ABAQUSC (22) by means of a user-material subroutine (UMAT). An auxiliary external file that contains the nodal coordinates and mesh connectivity is also used. The independence of the finite element mesh (structured/unstructured and coarse/fine) was previously studied for the isotropic model (3).

The cohesive model proposed has been used to reproduce the experimental results of the mixedmode fracture tests (modes I and II) carried out on sandwich panel specimens. The model uses the experimentally measured parameters that describe the fracture behaviour of panels formed by two plates of laminated plasterboard of $12 \mathrm{~mm}$ thickness and a insulating rock wool core of $50 \mathrm{~mm}$ thickness (panels 12-50-12), shown in Table 2 (6). Three-point bend (TPB) fracture tests on $74 \times 74 \times$ $333 \mathrm{~mm}^{3}$ specimens were performed by following the RILEM 50-FMC (23) to obtain the fracture energy of the sandwich panel. The values of the longitudinal deformation modulus and traction strength were indirectly obtained from the test. The parameters are the average value of six characterisation tests.

In this section the numerical results obtained for the simulation of the experimental tests are presented. For simplicity, in the numerical analysis an exponential softening curve is adopted.

Figure 10 shows a deformed mesh, with finite elements with the embedded crack, used to simulate
TABLE 2. Mechanical properties of the sandwich panel tested (6).

\begin{tabular}{llll}
\hline $\begin{array}{l}\text { Panel type } \\
e-E L R-e\end{array}$ & $G_{F}(\mathrm{~N} / \mathrm{m})$ & $f_{t}(\mathrm{MPa})$ & $E(\mathrm{MPa})$ \\
$12-50-12$ & $\operatorname{Mean}(S)$ & $\operatorname{Mean}(S)$ & $\operatorname{Mean}(S)$ \\
\hline
\end{tabular}

$e=$ thickness of plasterboard surface $(\mathrm{mm})$.

$E L R=$ thickness of the rock wool core $(\mathrm{mm})$.

$G_{F}$ : specific fracture energy.

$f_{t}$ : tensile strength.

$E$ : Young's modulus.

Mean: average value obtained from six specimens

$S$ : standard deviation

the fracture of the sandwich panels of laminated plasterboard and rock wool specimens.

Figure 11 compares the numerical prediction of the model with the experimental results of the mixed-mode I and II fracture tests for the three sizes of sandwich panel specimens studied.

Figure 12 compares the crack trajectories obtained by the numerical model and the experimental ones for the mixed-mode I and II fracture tests of the three sizes of sandwich panel specimens.

Finally, Figure 13 shows the graphic of the size effect with error bars of the experimental and numerical results obtained. In the graphic, the nominal stress and the panel depth values have been parameterised as shown in point 3 of this work.

The model reproduces the experimental results of mixed-mode fracture tests only by using the experimental parameters of fracture of the material, and is capable of reproducing the size effect of the specimens.

\section{DISCUSSION}

The experimental results of the parameters adopted for the numerical modelling were obtained in a previous work (6). From this research, it can be observed that the fracture energy of laminated gypsum and that of rock-wool panels is highly conditioned by the thickness of rock wool and not significantly by the thickness of the laminated gypsum board. This is due to the composition of the rock wool, consisting of agglomerated fibres which 


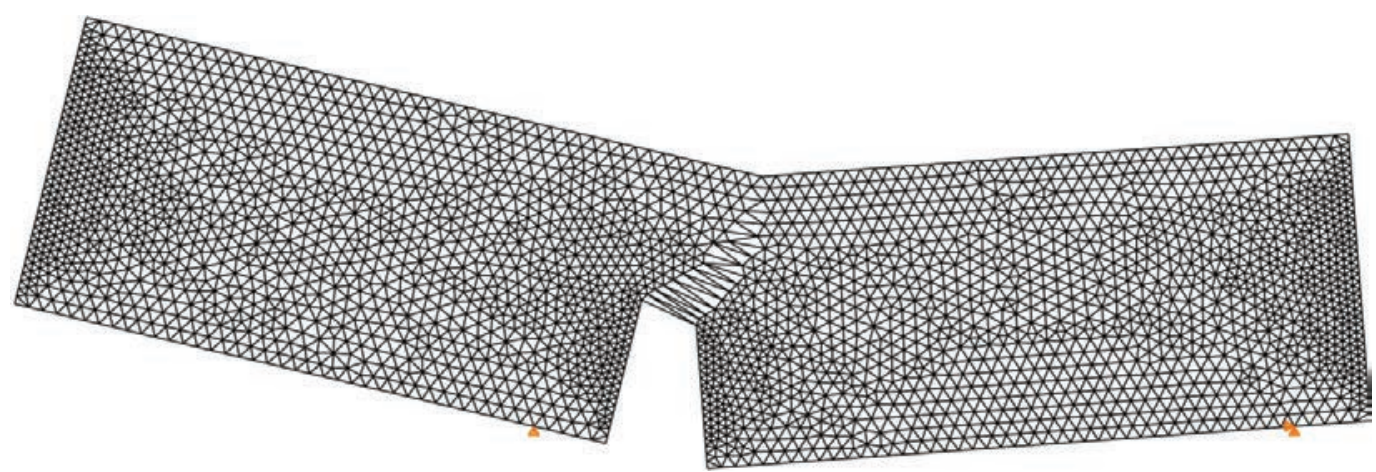

FIGURE 10. Finite element deformed mesh of a sandwich panel specimen under mixed-mode loading conditions.

a)

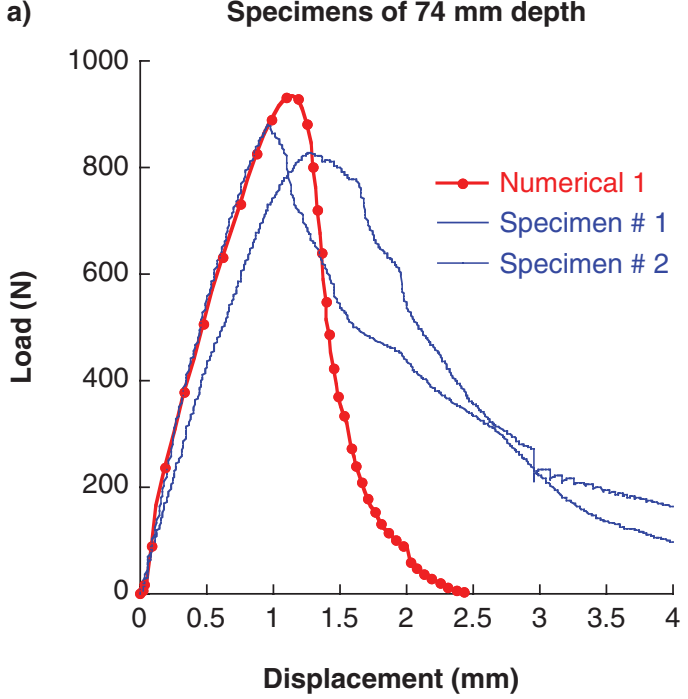

b) Specimens of $150 \mathrm{~mm}$ depth

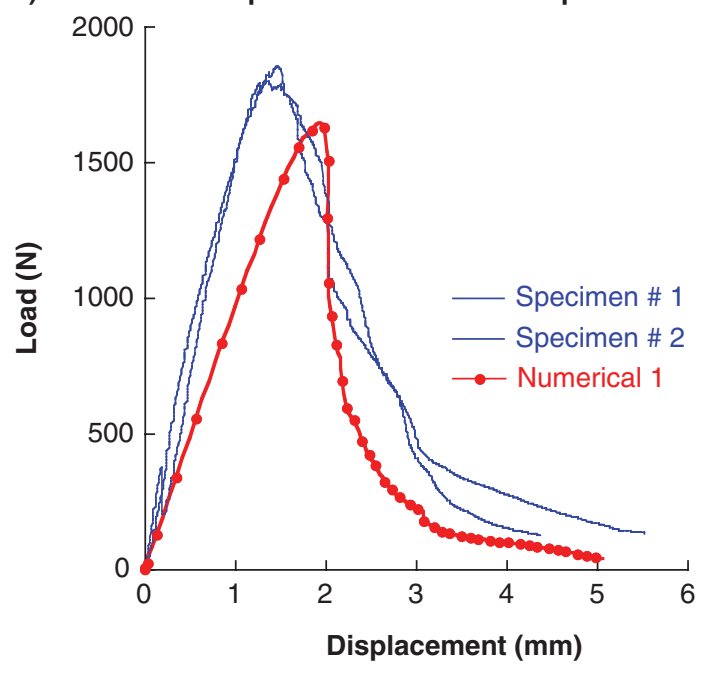

c)

Specimens of $290 \mathrm{~mm}$ depth

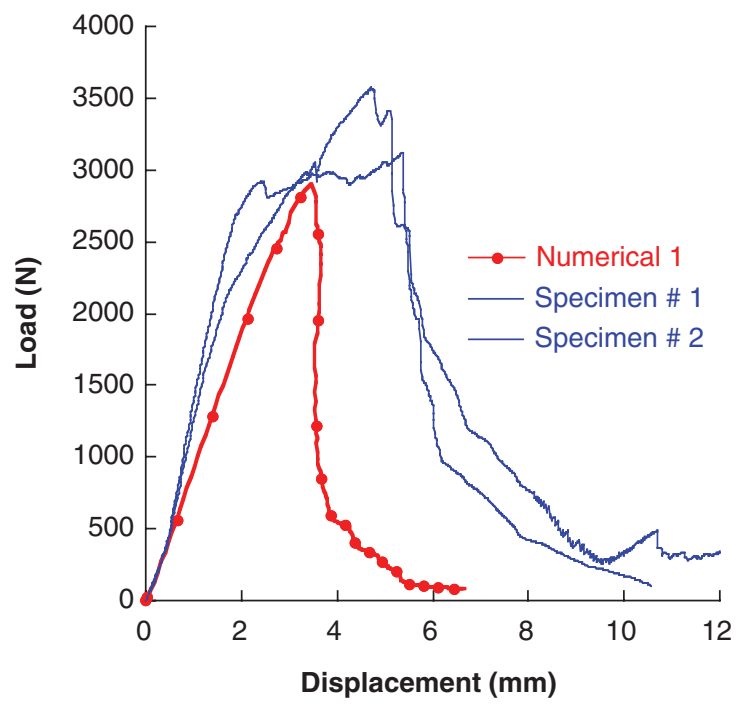

FIGURE 11. Fracture experimental results and numerical prediction of the mixed-mode fracture tests for different size specimens of 12-50-12 panel sandwich: a) $74 \mathrm{~mm}$ depth, b) $150 \mathrm{~mm}$ depth, c) $290 \mathrm{~mm}$ depth. 
a)

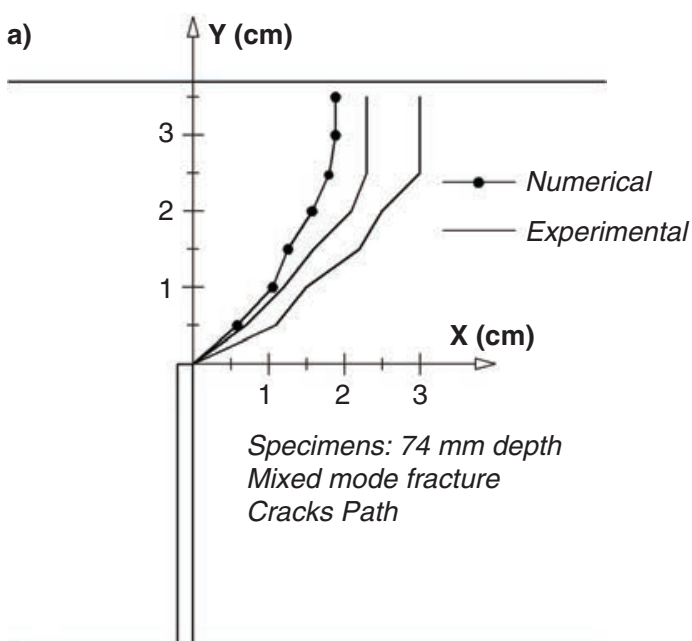

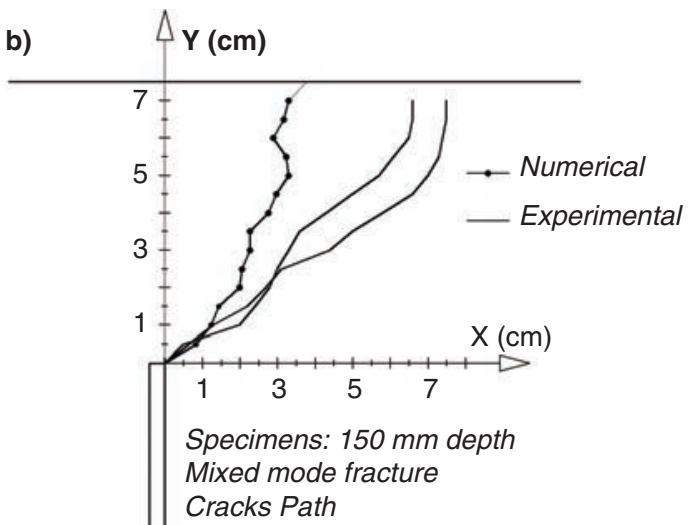

c)

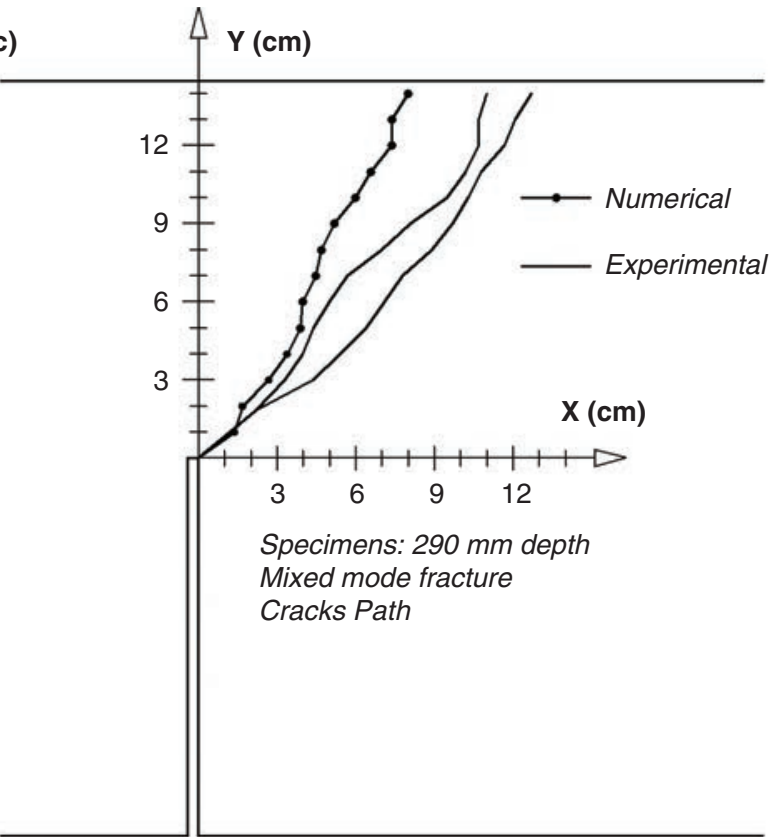

FIGURE 12. Experimental records and numerical prediction of the mixed-mode crack paths for different size specimens of 12-50-12 panel sandwich: a) $74 \mathrm{~mm}$ depth, b) $150 \mathrm{~mm}$ depth, c) $290 \mathrm{~mm}$ depth.

are capable of generating a large number of micro cracks during break, dissipating energy by friction between the fibers, and increasing the energy needed for the advancement of the fissure. Therefore, high specific fracture energy is obtained. In addition, any variation in the rock wool fibres might cause significant variation in the specific fracture energy and modulus of elasticity measured. A change in the production batch of sandwich panels might explain the scattering recorded in the parameters, as the specimens used in the tests were obtained from supplied commercial sandwich panels.

The numerical approach proposed does not make any distinction between laminated plasterboard and rock wool core, averaging the effect of the composite material through a fictitious continuous material. In the numerical analysis a simple exponential softening curve is used. As can be observed in Figure 11, the loading part of the curves is correctly predicted by the model, except for $150 \mathrm{~mm}$ height specimens. In this case, the stiffness of the experimental results is higher than the numerical one, probably because a variation in the item of the sandwich panel with a higher elastic modulus value than the obtained in the characterization value. The unloading branch of the curve is not so correctly captured by the analysis because the exponential law is too simple. The prediction of the unloading part might be improved by selecting a softening curve with a steeper initial descent and a stronger tail, as is the case of a bilinear type of softening. However, a search of the softening for a better fit has not been attempted because 


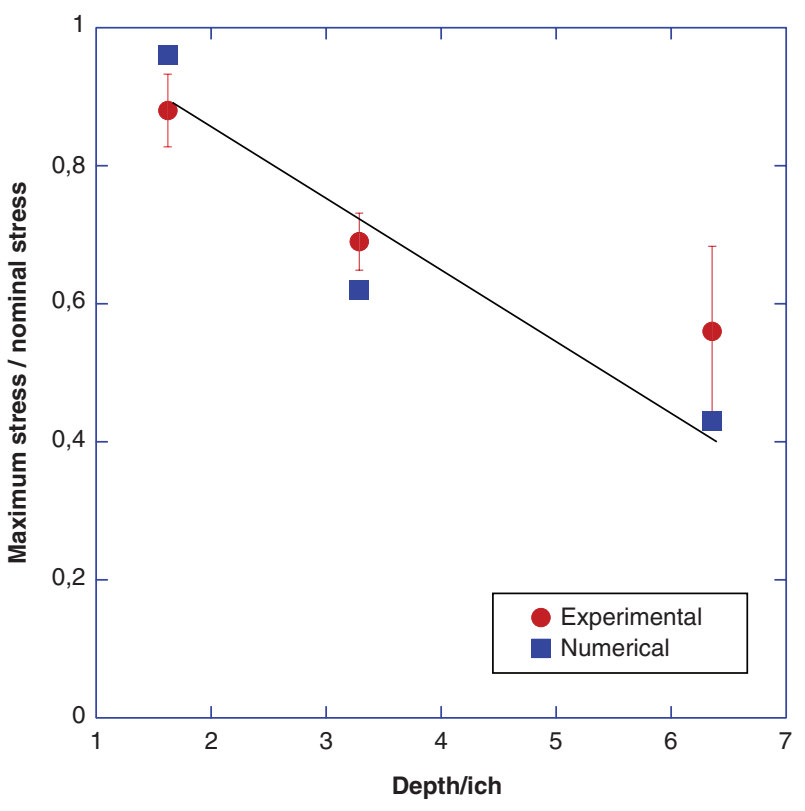

FIGURE 13. Experimental records and numerical prediction. Graphic of size effect for specimens of 74, 150 and $290 \mathrm{~mm}$ depth, of 12-50-12 panel sandwich.

this is out of the scope of the present research. The numerical results provided are conservative and sufficiently accurate.

Figure 12 shows quite deviation of the numerical crack trajectories from the experimental crack paths, even though the embedded crack model is able to reproduce correctly the shape of the real trajectories. The model uses a constant strain triangle with a straight crack line embedded, so the numerical crack trajectory described is highly influenced by the mesh refinement. A more accurate prediction could be achieved if the numerical analysis were performed once the real crack path is known. However, as this is not a predictive approach supplementary meshing work is needed.

As can be observed in Figure 13, the size effect is significant in this material. The classical size effect of the quasi-brittle materials, typical of the size of the specimens, is increased by the effect due to the relative influence of the volume of rock wool in relation to the size of the specimen. Thus, in smaller specimens, the influence of rock wool is greater than in the larger ones. In addition, some variations in the sandwich panels supplied might cause an apparent change of tendency of the differences between the experimental and numerical results. It is worth noting that the model only uses material parameters experimentally measured through standardised tests. These tests are independent and previously performed in the numerical modelling. In such a sense, the model is a predictive one which may be used for extrapolation studies. The proposed model procedure achieves a balance between accuracy and simplicity, and provides a helpful tool to predict the fracture of sandwich panel structural elements when a single macro-crack, or finite number of them, is the main failure mechanism.

\section{FINAL COMMENTS}

This work analyses the size effect of the mixedmode fracture in-plane of sandwich panels made of plaster with rock wool. The experimental fracture data for this material are scarce. The data supplied for performing this work has made characterization of this material easier and facilitated use of calculation models for studying cracking behaviour. This is a key point for studying the cracking of vertical interior partition in buildings under deflection of floor slabs and differential settlements.

The results obtained from the experimental campaign have shown that the fracture size effect in this material is significant because of the notable influence that it has on the fracture energy the core of rock wool.

The cohesive crack model, implemented in finite element with an embedded crack, supplies a good approach for modelling the fracture behaviour of sandwich panels made from plasterboard with core of rock wool. In addition, the model properly reproduces the size effect shown for this material under mixed-mode fracture loading conditions. The trajectory of the cracks is also modelled. The model may be used, from the practical point of view, for identifying the causes of the vertical interior partition cracking and limiting the slab deflection.

\section{ACKNOWLEDGEMENTS}

The authors gratefully acknowledge the financial support provided by Ministry of Economy, Industry and Competitiveness of Spain by means of the Research Fund Project BIA2016-78742-C2-2-R. They also offer their gratitude to TEZNOCUBER for supplying sandwich panels made from plasterboard and rock wool.

\section{REFERENCES}

1. Ministerio de la Vivienda (2011) Código Técnico de la Edificación. Documento Básico HR: Protección Frente al Ruido Madrid.

2. Ministerio de la Vivienda, C.S.I.C. Instituto Eduardo Torroja (2010) Catálogo de elementos constructivos del Código Técnico de la Edificación Madrid.

3. Sancho, J.M.; Planas, J.; Cendón, D.A.; Reyes, E. and Gálvez, J.C. (2007) An embedded crack model for finite element analysis of concrete fracture, Eng. Frac. Mech., 74 (1-2), 75-86. https://doi.org/10.1016/j. engfracmech.2006.01.015.

4. Reyes, E.; Gálvez, J.C.; Casati, M.J.; Cendón, D.A.; Sancho, J.M.; Planas, J. (2009) An embedded cohesive crack model for finite element analysis of brickwork masonry fracture. Eng. Frac. Mech, Vol 76, 1930-1944. https://doi.org/10.1016/j.engfracmech.2009.05.002 
5. Reyes, E.; Casati, M.J. and Gálvez, J.C. (2008) Experimental scale model study of cracking in brick masonry under tensile and shear stress. Mater. Contrucc., 58, 291, 69-83. https://doi.org/10.3989/mc.2008.v58.i291

6. Alonso, J.A.; Reyes,E. and Gálvez, J.C. (2013) Estudio de la fisuración de paneles sándwich de yeso laminado a alma de lana de roca. Mater. Contrucc, 63, 311, 403-421. https:// doi.org/10.3989/mc.2013.01412

7. Bazant,Z.P. (1984) Size effect in Blunt fracture: concrete, rock, metal, J. Eng. Mech., ASCE, Vol 110, 518-535.

8. Bazant,Z.P. ; Kim,J.K. (1984) Size effect in shear failure of longitudinally reinforced beams, ACI Journal, Vol 81, 456-468.

9. Asociación Española de Normalización y Certificación (2005) Norma UNE EN 520:2005. Placa de yeso laminado. Definiciones, especificaciones y métodos de ensayo Madrid.

10. Asociación Española de Normalización y Certificación (2002) Norma UNE EN 13.162:2002 Lana de roca. Definiciones, especificaciones y métodos de ensayo Madrid.

11. RILEM TC 89-FMT Fracture Mechanics of Concrete (1990) Size-effect method for determining fracture energy and process zone size of concrete. Mat. Struc., 23, 461-465.

12. Reyes, E. (2004) Fracture of the brickwork masonry under tensile/shear loading, Ph.D. Thesis (in Spanish), Ciudad Real, Spain.

13. Bažant, Z.P.; Planas, J (1998) Fracture and size effect in concrete and other quasibrittle materials. Boca Ratón, Florida : W.F. Chen, ed., CRC Press LLC.

14. Barenblatt, G.I. (1962) The mathematical theory of equilibrium of cracks in brittle fracture. Adv. Appl. Mech., Vol. 7, 55-129. https://doi.org/10.1016/S0065-2156(08)70121-2

15. Dugdale, D.S. (1960) Yielding of steel sheet sheets containing slits. J. Mech. Phys, Vol. 8, 100-108. https://doi. org/10.1016/0022-5096(60)90013-2
16. Hillerborg, A.; Modéer, M.; Petersson, P. E. (1976) Analysis of crack formation and crack growth in concrete by means of fracture mechanics and finite elements. Cem.t Concr. Res., 6, 773-782. https://doi.org/10.1016/ 0008-8846(76)90007-7

17. Sancho,J.M.; Planas, J.; Gálvez, J.C.; Reyes, E.;Cendón, D.A. (2006) An embedded cohesive crack model for finite element analysis of mixed mode fracture of concrete. Fatigue Fract Engng Mater Struct, Vol. 29, 1056-1065.. https://doi.org/10.1111/j.1460-2695.2006.01076.x

18. Simó, J.; Oliver J.; Armero F. (1993) An analysis strong discontinuities induced by strain softening in rate-independent inelastic solids Comput. Mech., Vol 12, 277-96. https://doi. org/10.1007/BF00372173

19. Cendón, D.A.; Gálvez, J.C.; Elices, M.;Planas, J (2000) Modelling the fracture of concrete under mixed loading. Int. J. Fract., Vol. 103, 293-310. https://doi.org/ 10.1023/A:1007687025575

20. Gálvez, J.C.; Cendón, D.A.; Planas, J. (2002) Influence of shear parameters on mixed- mode fracture of concrete. Int. J. Fract,.118, 163-189. https://doi.org/10.1023/ A: 1022883132117

21. Oliver, J. (1996) Modelling strong discontinuities in solid mechanics via strain softening constitutive equations. Part 1: fundamentals. Part 2: numerical simulations. Int. J. Num. Meth. Eng., 39, 3575-3623. https://doi.org/ 10.1002/(SICI)1097-0207(19961115)39:21<3575::AIDNME65>3.0.CO;2-E

22. ABAQUS (2017) Standard User's Manual, Version 6.14, Rhode Island, USA.

23. RILEM 50-FMC Committee Fracture Mechanics of Concrete (1986) Determination of the fracture energy of mortar and concrete by means of three-point bend tests on notched beams. Materials and Structures, vol. 18, 285-290 